\title{
The Effect of Transurethral Enucleation Resection of the Prostate for Benign Prostatic Hyperplasia on Immune and Stress Response
}

\author{
Bo-xiang Yuan, Bin Pan, Hui-lan Zeng, Yong-lu Wu, Shao-jiang Wang, Jie Chen* \\ Department of Urology, the First Affiliated Hospital of Jinan University, Guangzhou, China \\ Email address: \\ 744508642@qq.com(Jie Chen) \\ ${ }^{*}$ Corresponding author
}

\section{To cite this article:}

Bo-xiang Yuan, Bin Pan, Hui-lan Zeng, Yonglu Wu, Shao-jiang Wang, Jie Chen. The Effect of Transurethral Enucleation Resection of the Prostate for Benign Prostatic Hyperplasia on Immune and Stress Response. Journal of Surgery. Vol. 4, No. 5, 2016, pp. 95-99. doi: $10.11648 /$ j.js.20160405.12

Received: August 4, 2016; Accepted: August 13, 2016; Published: September 2, 2016

\begin{abstract}
This thesis aims to examine the effects of the systemic immune response triggered by the transurethral enucleation and resection of the prostate (TRERP). 60 patients with benign prostatic hyperplasia (BPH) were randomly classified into enucleation group and resection group. The level of WBC, serum IL-6, IL-8, CRP, IgG, IgA, IgM, CD4+, CD8+, and ratio of $\mathrm{CD} 4+$ to $\mathrm{CD} 8+(\mathrm{BPH})$ were compared and analyzed preoperatively and on the 1st, 3rd, 5th of postoperative day. The result demonstrates the statistical significance of the differences between the two groups on the amount of resected tissues, postoperative blood loss, and operation time. To the contrary, there was no statistical significance of the differences on WBC, IL-6, IL-8 and CRP level. To elaborate, on the 1st postoperative day, the values of WBC, IL-6, IL-8 and CRP level were significantly higher, whereas the values of $\operatorname{IgG}, \operatorname{IgA}, \mathrm{IgM}, \mathrm{CD} 4+, \mathrm{CD} 8+$ level and ratio of CD4+ to CD8+ of both groups were significantly lower. On the 3rd postoperative day, there was statistical significance of the differences between two groups on WBC, IL-6, IL-8, CRP level. On the 5th post operative day, however, no statistical significance of differences existed on the IgG, IgA, IgM, CD4+, CD8+ level and ratio of $\mathrm{CD} 4+$ to $\mathrm{CD} 8+$. It is concluded that compared to the transurethral resection of the prostate (TURP) for Benign prostatic hyperplasia (BPH), TRERP has prominent advantages of more radical resection, less blood loss and less immune suppression.
\end{abstract}

Keywords: Transurethral Enucleationof Prostate, Transurethral Resection of Prostate, Trauma, Stress Response

\section{Introduction}

The Benign prostatic hyperplasia (BPH), common seen among the elderly male, may trigger the lower urinary tract symptoms which have a serious impact on the life quality of the patients. There are approximately $20 \%$ of them requiring a surgical treatment $[1,2]$. Granted, the transurethral resection of the prostate (TURP) is regarded as the golden standard in treating BPH. This approach, however, is still insufficient in several aspects such as incomplete glands-cutting, postoperative reoccurrence, and infective complications $[3,4]$. Recently, an ingenious minimally invasive endoscopic technology known as transurethral enucleation and resection of prostate (TUERP) has emerged for BPH treatment [5]. Compared to the conventional TURP technique, the TUERP bears clear advantages of better security, less blood loss and surgery time, and more complete glands-cutting [6-8].

As a special form of trauma, surgery will trigger the stress response which can stimulate the immune supression and homeostasis changes. To stimulate the mononuclear phagocyte system, for instance, can secrete a variety of cytokines such as interleukin (IL), white blood cell (WBC) and C-reactive protein (CRP) [9, 10]. The elevation of these cytokines closely corelates with the extent of surgical trauma. Granted, the transurethral enucleation and resection of prostate is minimally invasive. As a risky operation, however, it will inevitably trigger the stress response and supression of cellular immune function [11]. Currently, hardly any relevant studies have been published about the impact of postoperative immune function and stress response. Further research should 
be done to Table out whether TUERP will increase petioperative risk and speed up the patients' recovery. By comparing the effect of Transurethral resection of the prostate (TURP) on immune and stress response to that of Transurethral enucleation and resection of prostate (TUERP), this thesis demonstrates the relative alternation and changes triggered by the urethral minimally invasive surgery.

\section{Materials and Methods}

\subsection{Study Design}

Sixty patients with BPH were enrolled between January 2013 and February 2014 from in patients, who age between 56 to 85 (the average age was $68.9 \pm 7.1$ ). Used random number table randomly divides 60 participants into the TUERP group and the TURP group. There was no statisticallydifference in age, IPSS, prostate volume, QOL score and the maximum flow rate (Qmax) between two group (Table 1). Clinical manifestation of patients in two groups had various degrees of dysuria and history of retention of urine, digital rectal examination, prostate sonography, MR imaging in assessing the pelvic cavity, and the PSA test for prostate cancer. The exclusion criteria for this study included patients with severe infection, and combination of hepatic and renal dysfunction, diabetes mellitus, coronary heart disease, immune system disease and patients with hormone therapy.

Table 1. Comparison the general index pre-operation between the TUERP group and the TURP group.

\begin{tabular}{|c|c|c|c|c|c|c|}
\hline Group & $\operatorname{Age}(y / 0)$ & Prostate Volume (ml) & PSA (ng/ml) & IPSS & QOL & Qmax (ml/s) \\
\hline The TUERP group & $70.5 \pm 7.4$ & $61.3 \pm 18.1$ & $2.5 \pm 0.7$ & $22.9 \pm 5.6$ & $5.0 \pm 1.1$ & $9.2 \pm 2.5$ \\
\hline The TURP group & $67.4 \pm 6.3$ & $60.1 \pm 19.6$ & $2.6 \pm 0.6$ & $21 \pm 6.1$ & $4.9 \pm 1.5$ & $8.5 \pm 2.3$ \\
\hline
\end{tabular}

\subsection{Experimental Method}

Application of automated hematology analyzer (Beckman Coulter lnc.) determine peripheral white blood cell count. Using the immune turbidity analysis quantitative detect serum CRP concentration (kid was provided by the US Roche company). Apply ELISA detect IL-6, IL-8 (kid was provided by Shanghai Heng yuan Biochemicals Ltd.)

\subsection{Operation Methods}

All operations in two groups were done or supervised by a single chief surgeon. Under spinal anesthesia the patient was placed in the lithotomy position. Transurethral enucleation andresection of the prostate (TUERP), using the Gyrus plasma kinetic system, is a unique surgery which was initiated and propagated at a 2006 AUA Meeting. The TURP group resected hyper-plastic prostate tissue till the plane of the prostatic capsule by applying plasma kinetic resection of prostate. While, unique feature of TUERP is that the prostate is transurethrally enucleated and resected using a bipolar plasma kinetic resectoscope.The procedure was performed as follows.To develop the plane of surgical capsule, the hyperplasia prostate tissuewas dissected from the capsule plane. The blood vessels to the hyperplasia were coagulated at the time of dissection.Then, retrograde transurethral resected prostatic hyperplasia tissue [5]. After flushing out the prostate tissue of both groups, indwelling urinary catheter for 7 days and continuous bladder irrigation for one day.

\subsection{Measures}

All patients were assessed perioperatively and followed at the 1st, 3th and5th day postoperatively.The preoperative and postoperative parameters includedthe level of peripheral white blood cell (PWBC), C-reactive protein (CRP), IL-6, IL-8. Patient baseline characteristics, perioperative data, and postoperative outcomes were compared.Record the duration of operation, blood loss during operation, the amount of the resected tissues, and postoperative complication, etc.

\subsection{Statistical Analysis}

We conducted a statistical analysis by using SPSS13.0 analysis software. We showed the data by $\overline{\mathrm{X}} \pm \mathrm{S}$. Measurement data were examined by the mean number of two samples. $\mathrm{P}<0.05$ is considered as statistically significant.

\section{Results}

Patients in two groups were completed operation successfully. Blood lossduring the operation in the TUERP group and the TURP group were $90.2 \pm 18.2 \mathrm{ml}$ and $110,0 \pm 20.6 \mathrm{ml}$ respectively $(\mathrm{P}<0.05)$. The amount of resected tissues in the TUERP group and the TURP group were $44.8 \pm 4.3 \mathrm{ml}$ and $31.1 \pm 2.8 \mathrm{ml} \quad(\mathrm{P}<0.05)$. The duration of operation in the TUERP group and the TURP group were $43.4 \pm 10.1 \mathrm{~min}$ and $54.6 \pm 9.9 \mathrm{~min}(\mathrm{P}<0.05)$. The results showed that compared with baseline both groups' IPSS was decreased and Qmax was increased significantly at 6 to 14 months follow-up postoperatively $(\mathrm{P}<0.05)$. Moreover, there was no significant difference between two groups $(\mathrm{P}>0.05)$. All patients in two groups without urinary incontinence and urethral stricture and other complications postoperatively.

There were no significant difference of the level of PWBC, IL-6, IL-8 and CRP between two groups at baseline $(\mathrm{P}>0.05)$. At the first day postoperatively, the level of PWBC, IL-6, IL-8 and CRP in two groups were significantly higher that baseline $(\mathrm{P}<0.05)$.At the 3th day postoperatively, there were statistically different between two groups of the level of PWBC, IL-6, IL- 8 and CRP $(\mathrm{P}<0.05)$. At the 5th day after operation, the levels of PWBC, IL-6, IL-8 and CRP in two groups were similar to the level at baseline. There were no statistically significant (Table 2). 
Table 2. The change of the level of PWBC, IL-6, IL-8 and CRP.

\begin{tabular}{|c|c|c|c|c|c|}
\hline Group & & Baseline & 1st day & 3th day & 5th day \\
\hline \multirow[t]{4}{*}{ TUERP } & WBC $\left(10^{9} / \mathrm{L}\right)$ & $5.3 \pm 0.9$ & $8.3 \pm 1.2 *$ & $6.8 \pm 0.9^{*}$ & $5.9 \pm 0.8$ \\
\hline & $\mathrm{CRP}(\mathrm{mg} / \mathrm{L})$ & $5.8 \pm 1.3$ & $42.9 \pm 5.6^{*} \Delta$ & $33.0 \pm 7.0 * \Delta$ & $8.5 \pm 3.3$ \\
\hline & IL-6(pg/mL) & $7.4 \pm 2.6$ & $53.2 \pm 9.4 * \Delta$ & $24.7 \pm 7.8 * \Delta$ & $10.9 \pm 2.6$ \\
\hline & IL- $8(\mathrm{pg} / \mathrm{mL})$ & $96.3 \pm 13.7$ & $114.5 \pm 10.9 * \Delta$ & $104.3 \pm 11.3 * \Delta$ & $99.3 \pm 10.8$ \\
\hline \multirow[t]{3}{*}{ TURP } & WBC $\left(10^{9} / \mathrm{L}\right)$ & $5.4 \pm 0.8$ & $9.2 \pm 1.4^{*}$ & $7.2 \pm 1.0 *$ & $6.0 \pm 0.9$ \\
\hline & CRP(mg/L) & $6.0 \pm 1.5$ & $50.0 \pm 6.8^{*}$ & $39.2 \pm 8.3^{*}$ & $10.2 \pm 3.8$ \\
\hline & IL-6(pg/mL) & $6.4 \pm 2.0$ & $60.5 \pm 11.9 *$ & $33.4 \pm 9.4^{*}$ & $11.5 \pm 2.9$ \\
\hline
\end{tabular}

Compared to baseline, ${ }^{*} \mathrm{P}<0.05$. Comparison between the two groups, $\triangle \mathrm{P}<0.05$

There is no noticeable discrepancy of the patients in the two groups in the percentage of $\operatorname{IgG}, \operatorname{IgA}, \operatorname{IgM}, \mathrm{CD} 4+, \mathrm{CD} 8+$, and the variation of $\mathrm{CD} 4+/ \mathrm{CD} 8+$ in preoperative phase $(\mathrm{P}>0.05)$. On the first postoperative day, those values are considerably lower than that of the preoperative phase ( $\mathrm{P}>0.05)$. The difference between the two groups, however, was not statistically significant. The same is true with the comparison of those values on the $3 \mathrm{rd}$ and 5 th postoperative day to that of the preoperative phase, as shown in Table 3and 4.

Table 3. Variation of $\operatorname{Ig} G$, $\operatorname{Ig} A$ and $\operatorname{Ig} M$ in serum of two groups.

\begin{tabular}{lllll}
\hline Group & & Baseline & 1st day & 3th day \\
\hline TUERP & IgG & $13.98 \pm 1.24$ & $9.92 \pm 2.1^{*}$ & $12.54 \pm 1.15$ \\
& IgA & $2.96 \pm 0.42$ & $2.61 \pm 0.38^{*}$ & $3.13 \pm 0.62$ \\
& IgM & $1.75 \pm 0.53$ & $0.58 \pm 0.13^{*}$ & $1.91 \pm 0.47$ \\
TURP & IgG & $13.48 \pm 1.11$ & $10.45 \pm 1.27^{*}$ & $12.34 \pm 1.04$ \\
& IgA & $3.08 \pm 0.49$ & $2.48 \pm 0.35^{*}$ & $3.20 \pm 0.55$ \\
& IgM & $1.81 \pm 0.59$ & $0.61 \pm 0.14^{*}$ & $1.81 \pm 0.57$ \\
\hline
\end{tabular}

Compared to that of preoperative phase, ${ }^{*} \mathrm{P}<0.05$

Table 4. Variation of $C D 4+, C D 8+$ as well as $C D 4+/ C D 8++$ in serum of two groups.

\begin{tabular}{llllll}
\hline Group & & Baseline & 1st day & 3th day \\
\hline TUERP & CD4+ & $41.9 \pm 8.1$ & $34.5 \pm 6.9^{*}$ & $39.1 \pm 7.9$ \\
& CD8+ & $33.5 \pm 5.3$ & $31.7 \pm 4.6^{*}$ & $32.2 \pm 6.0$ \\
& CD4+/CD8+ & $1.29 \pm 0.24$ & $1.03 \pm 0.14^{*}$ & $1.17 \pm 0.11$ \\
TURP & CD4+ & $41.3 \pm 7.1$ & $35.6 \pm 7.1^{*}$ & $39.3 \pm 8.1$ \\
& CD8+ & $33.8 \pm 5.4$ & $31.3 \pm 4.5^{*}$ & $32.9 \pm 5.7$ \\
& CD4+/CD8+ & $1.27 \pm 0.26$ & $1.01 \pm 0.12^{*}$ & $1.16 \pm 0.14$ \\
\hline
\end{tabular}

Compared to that of the preoperative phase, $* \mathrm{P}<0.05$

\section{Discussion}

TUERP mimics open prostectomy in terms of identifying the plane between the adenoma and the prostatic capsule and mechanical enucleation of the adenoma from the prostatic capsule [12]. Recent study suggests that TUERP is a safe and feasible treatment for BPH with few complications, especially in patients with larger prostates $[5,13,14]$. In this study, we compared TUERP with TURP. After the operation, both groups improved IPSS, QOL, Qmax significantly when compared with the baseline. It indicated that TUERP and TURP are effective treatment for BPH. Moreover, surgical trauma produces can cause the alterations of immune homeostasis of patients after operation [15]. Large-scale population researches have indicated that prostatism associated with age specific incidences of symptoms. Thus, it is necessary to pay more attention to elderly patients with BPH $[16,17]$. Furthermore, the change of immune homeostasis might cause peri-operative risk increased which against the rehabilitation of patients. The degree of the stress response is relative to the degree of surgical trauma. Thus, the reduction of surgical trauma is particularly important to stress response postoperatively. There was research suggested that minimally invasive surgery causes less tissue injury than conventional procedures. It has been shown to produce a reducedthe concentrations of biochemical markers of inflammation such as IL-6, IL-8 and CRP [18, 19]. It also indicated that minimally invasive surgery can prevent damage to body caused by the strong inflammatory reaction [20]. However, little research was conducted to investigate the impact of immunologic function after the transurethral resection of the prostate surgery.

It had been shown that surgical trauma induces acute phase response and inhibits cellular immense function in the postoperative period [18]. Additionally, the degree of inhibition is closely associated to the size of the surgical trauma, the amount of blood loss of the surgery and the duration of the operation [11, 21, 22]. It has been indicated that the degree of surgical trauma is positively related to the concentration of IL-6 and IL-8. Specifically, blood circulating levels of IL- 6 can be increased within 1 to 3 hours after surgery. The level of IL-6 is associated with duration of surgery, the amount of blood loss and the degree of surgical 
trauma. Also, postoperative complications and mortality rate are related to IL-6 level too high and its duration too long [22]. CRP is an acute phase protein which synthesized by liver cell mediating by IL-6. It is a reliable index of acute phase reaction which was induced by surgery [23, 24]. It is increased 4 to 12 hours after surgery and reach to the peak within 1 to 2 days [25]. In this study, the levels of CRP, IL-8 and IL-6 increased significantly after the first day of the operation and reached the peak at the third day and it decreased slowly afterwards. This results are similar to the relevant researches [8]. These results indicated that both TUERP and TURP can induce stress response. Additionally, stress response caused by surgery can regulate the change of homeostasis, which is reversible immune suppression.

Additionally, in this study, total number of WBC was increased in both groups postoperatively. At the third day postoperatively, there were no statistically difference between the TUERP group and the TURP group. It can be suggested that in terms of the acute inflammatory reaction, the total number of WBC increased significantly postoperatively. However, the TUERP caused less acute inflammatory response compared to the TURP. Moreover, the levels of IL-6, IL-8 and CRP increased obviously after the operation when compared to the baseline. Specifically, the levels of IL-6, IL-8 and CRP in the TUERP group significantly lower than the TURP group at the first and third day $(\mathrm{P}<0.05)$. These findings suggested that both the TUERP and TURP have an impact on the immune suppression. However, less stress reaction was found in the TUERP group. We found that the TUERP has advantages of shorter operation time, less bleeding, less conductive trauma, less stimulation, less impact on immune function and neuroendocrine function and less acute inflammatory response. To a certain extent, it protects immune function and leads to shorter postoperative recovery time. However, the study contained smaller sample size which could not reach a statistically significant for various outcome measures. Further clinical investigations are needed to evaluation the difference systemic immune response between TRERP and TURP for BPH.

The surgical trauma can cause the body's comprehensive immune response and alter the function of $\mathrm{T}$ lymphocyte subsets, which will result in the reduction of IgG, CD4+ and $\mathrm{CD} 8+$. As a critical immune effect factor, IgG presents a concentration decline in serum when the body suffers from trauma, the extent of which is bound up with severity of trauma [26, 27].

The research indicates that the decreased ratio after surgical trauma is reversible and There were difference between two groups at baseline the minimally invasive and open surgery $[28,29]$. The results show that the values of IgG, IgA, IgM, $\mathrm{CD} 4+, \mathrm{CD} 8+$ and $\mathrm{CD} 4+/ \mathrm{CD} 8+$ of the patients in both groups in an immunosuppressive state are considerably less on the fist postoperative day than that of pre-operation. On the 7 th postoperative day, each index returns to preoperative levels, which indicates a reversible immunosuppression, fast recovery and better preservation of immune function of preoperative patients [30].

\section{Conclusion}

TUERP is operation which is more thorough removal of the prostate, less bleeding, safer and less negative impact on immune response. It is worthy of promotion and application in the clinical field.

\section{Contribution}

Bo-xiang Yuan and Bin Pan contributed equally to this study, they are the first author together.

\section{References}

[1] Malmsten UG, Molander U, Peeker R, Irwin DE, Milsom I. Urinary incontinence, overactive bladder, and other lower urinary tract symptoms: A longitudinal population-based survey in men aged 45- 103 years. Eur Urol 2010;58: 149-156.

[2] Kousei M, Yoshinori N, Mina K, Masue T, Moriyama Y, Deguchi T. Efficacy of combination therapy with tamsulosin and zolpidem on nocturia in patients with benign prostatic hyperplasia. Cent European J Urol 2011; 64: 232-5.

[3] Rassweiler J, Teber D, Kuntz R, Hofmann R. Complications of transurethral resection of the prostate (TURP)--incidence, management, and prevention. Eur Urol 2006; 50: 969-79.

[4] Varkarakis J, Bartsch G, Horninger W. Long-term morbidity and mortality of transurethral prostatectomy: a 10-year follow-up. Prostate 2004; 58: 248-251.

[5] Liu C, Zheng S, Li H, Xu K. Transurethral enucleation and resection of prostate in patients ith benign prostatic hyperplasia by plasma kinetics. J Urol 2010; 184: 2440-5.

[6] Kim M, Lee HE, Oh SJ. Technical aspects of holmium laser enucleation of the prostate for benign prostatic hyperplasia. Korean J Urol 2013; 54: 570-9.

[7] Sun N, Fu Y, Tian T, Gao J, Wang Y, Wang S, et al. Holmium laser enucleation of the prostate versus transurethral resection of the prostate: A randomized clinical trial. Int Urol Nephrol 2014; 46: 1277-1282.

[8] Pan B, Deng Z, Jiao G, Lai C, Su Z, Liu J. Long-term Follow-up of Transurethral Enucleation Resection of the Prostate for Symptomatic Benign Prostatic Hyperplasia. J Surg 2016; 4: 40-4.

[9] Veenhof AA, Sietses C, von Blomberg BM, van Hoogstraten IM, vd Pas MH, Meijerink WJ, et al. The surgical stress response and postoperative immune function after laparoscopic or conventional total mesorectal excision in rectal cancer: a randomized trial. Int J Colorectal Dis 2011; 26: 53-9.

[10] Tsimogiannis KE, Telis K, Tselepis A, Pappas-Gogos GK, Tsimoyiannis EC, Basdanis G. A-defensin expression of inflammatory response in open and laparoscopic colectomy for colorectal cancer. World J Surg 2011; 35: 1911-7.

[11] Styliani Karanika, Theodoros Karantanos, George E. Immune response after laparoscopic colectomy for cancer: a review. Gastroenterol Rep (Oxf) 2013; 1: 85-94.

[12] Seki N, Naito S. Instrumental treatments for benign prostatic obstruction. Curr Opin Urol 2007; 17: 17-21. 
[13] Neill MG, Gilling PJ, Kennett KM, Frampton CM, Westenberg AM, Fraundorfer MR, et al. Randomized trial comparing holmium laser enucleation of prostate with plasmakinetic enucleation of prostate for treatment of benign prostatic hyperplasia. Urology 2006; 68: 1020-4.

[14] Zhao Z, Zeng G, Zhong W, Mai Z, Zeng S, Tao X. A prospective, randomised trial comparing plasmakinetic enucleation to standard transurethral resection of the prostate for symptomatic benign prostatic hyperplasia: three-year follow-up results. Eur Urol 2010; 58: 752-8.

[15] Ni Choileain N, Redmond HP. Cell response to surgery. Arch Surg 2006; 141: 1132-40.

[16] Ben-Zvi T, Hueber PA, Liberman D, Valdivieso R, Zorn KC. Green Light XPS 180W vs HPS 120W laser therapy for benign prostate hyperplasia: a prospective comparative analysis after 200 cases in a single-center study. Urology 2013; 81: 853-8.

[17] Garraway WM, Collins GN, Lee RJ. High prevalence of benign prostatic hypertrophy in the community. Lancet 1991; 338: 469-71.

[18] Halevy A, Lin G, Gold-Deutsch R, Lavi R, Negri M, Evans S,et al. Comparison of serum C-reactive protein concentrations for laparoscopic versus open cholecystectomy. Surg Endosc 1995; 9: $280-2$.

[19] Cho JM, La Porta AJ, Clark JR, Schofield MJ, Hammond SL, Mallory PL 2nd. Response of serum cytokines in patients undergoing laparoscopic cholecystectomy. Surg Endosc 1994; 8: $1380-3$.

[20] Kehlet H. Multimodal approach to control postoperative pathophysiology and rehabilitation. Br J Anaesth 1997; 78: 606-17.

[21] Decker D, Schondorf M, Bidlingmaier F Hirner A, von Ruecker AA. Surgical stress induces a shift in the type-1/type-2 T-helper cell balance, suggesting down regulation of cell-mediated and upregulation of antibody-mediated immunity commensurate to the trauma. Surgery 1996; 119: 316-25.
[22] Schietroma M, Carlei F, Franchi L, Mazzotta C, Sozio A, Lygidakis NJ, et al. A comparison of serum interleukin-6 concentrations in patients treated by cholecystectomy via laparotomy or laparoscopy. Hepato gastroenterology 2004; 51: 1595-9.

[23] Ordemann J, Jacobi CA, Schwenk W, Stösslein R, Müller JM. Cellular and humoral inflammatory response after laparoscopic and conventional colorectal resections: results of a prospective randomized trial. Surg Endosc 2001; 15: 600-8.

[24] Lennard TW, Shenton BK, Borzotta A, Donnelly PK, White M, Gerrie LM, et al. The influence of surgical operations on components of the human immune system.Br J Surg 1985; 72: 771-6.

[25] Kuhry E, Jeekel J, Bonjer HJ. Effect of laparoscopy on the immune system. Semin LaparoscSurg 2004; 11: 37-44.

[26] Altamura M, Tafaro A, Casale D, Pepe M, Colella R, Jirillo E, et al. A comparative study between conventional and laparoscopic cholecystectomy: Evaluation of phagocytic and T-cell-mediated antibacterial activities. J Clin Gastroenterol 2002; 34: 135-40.

[27] Wilgus TA, Roy S, McDaniel JC. Neutrophils and Wound Repair: Positive Actions and Negative Reactions. Adv Wound Care (New Rochelle) 2013; 2: 379-388.

[28] Liu C, Liu J, Zhang S. Laparoscopic versus conventional open surgery for immune function in patients with colorectal cancer. Int J Colorectal Dis 2011; 26: 1375-85.

[29] Tang CL, Eu KW, Tai BC, Soh JG, Mac Hin D, Seow-Choen F. Randomized clinical trial of the effect of open versus laparoscopically assisted colectomy on systemic immunity in patients with colorectal cancer. Br J Surg 2001; 88:801-7.

[30] Peng B, Zheng JH, Li H. Effect of retroperitoneal laparoscopic radical nephrectomy of renal carcinoma (nephroma) on perioperative cell immunity. J Endourol 2008; 22: 2161-4. 